\title{
Soluble Receptor for Advanced Glycation End Product: A Biomarker for Acute Coronary Syndrome
}

\author{
Louise J. N. Jensen, Allan Flyvbjerg, and Mette Bjerre \\ The Medical Research Laboratory, Department of Clinical Medicine, Aarhus University, 8000 Aarhus C, Denmark \\ Correspondence should be addressed to Mette Bjerre; mette.bjerre@ki.au.dk
}

Received 9 July 2015; Revised 14 September 2015; Accepted 15 September 2015

Academic Editor: Renzhi Han

Copyright ( 2015 Louise J. N. Jensen et al. This is an open access article distributed under the Creative Commons Attribution License, which permits unrestricted use, distribution, and reproduction in any medium, provided the original work is properly cited.

The receptor of advanced glycation end products (RAGE) and its ligands are linked to the pathogenesis of coronary artery disease (CAD), and circulating soluble receptor of advanced glycation end products (sRAGE), reflecting the RAGE activity, is suggested as a potential biomarker. Elevated sRAGE levels are reported in relation to acute ischemia and this review focuses on the role of sRAGE as a biomarker for the acute coronary syndrome (ACS). The current studies demonstrated that sRAGE levels are elevated in relation to ACS, however during a very narrow time period, indicating that the time of sampling needs attention. Interestingly, activation of RAGE may influence the pathogenesis and reflection in sRAGE levels in acute and stable CAD differently.

\section{Introduction}

Worldwide, cardiovascular disease (CVD) is a prominent cause of increased morbidity and mortality with a heavy burden on the health care system [1]. Even though improvements in prevention, diagnosing, and treatment of the disease have increased substantially during the last decades, more attention is needed. It is believed that inflammatory mechanisms are involved in the development of CVD [2,3], though the detailed pathogenic role of the inflammation system is still under investigation. The receptor of advanced glycation end products (RAGE) is found to play an important role in the development of CVD [4], and the soluble RAGE (sRAGE) may to some extent reflect RAGE activity, thus increasing the value of sRAGE as a biomarker $[5,6]$. This review focuses on the role of sRAGE as a biomarker for the acute coronary syndrome (ACS).

\section{Receptor for Advanced Glycation End Products (RAGE)}

RAGE is a transmembrane receptor of the immunoglobulin superfamily composed of three domains: an extracellular domain binding to ligands, a hydrophobic membrane spanning domain, and a highly charged cytoplasmic domain essential for the intracellular signaling. RAGE is expressed in many cell types including endothelial cells, lymphocytes, monocytes, and vascular smooth muscle cells. RAGE expression is minimal under normal conditions but increases significantly during cellular stress $[7,8]$.

RAGE was first described as a receptor for advanced glycation end products (AGEs) and it was initially linked to hyperglycemia, diabetes, and diabetic complications [9]. However, RAGE is now characterized as a multiligand receptor [10], and, apart from AGEs, RAGE interacts with other ligands, such as the S100 proteins [11], high mobility group box 1 (HMGB1) [12, 13], and amyloids [14]. Ligand binding is described to increase RAGE activity $[15,16]$, which mediates proinflammatory responses [17-19] and generates oxidative stress $[15,18,20]$ that may contribute to the pathogenesis of CVD. Still, the exact function in vascular pathogenesis is unclear.

Mechanistic studies showed that cardiomyocytes upregulated both RAGE and AGEs after exposure to hypoxia followed by reoxygenation. Furthermore, cardiomyocytes isolated from genetic RAGE knockout or from mice pretreated with sRAGE showed protection against cellular damage [21]. Similarly, RAGE expression increased in mice myocardium after a temporary occlusion of the left anterior descending artery compared to sham-operated animals and RAGE 
colocalized with apoptotic cardiomyocytes [22]. The infarct sizes diminished in RAGE knockout mice hearts exposed to I/R injury [23] and precursors of RAGE ligands were reduced [24]. Furthermore, RAGE knockout mice or mice treated with RAGE inhibitors had less impaired cardiac function $[12,23-25]$ and diminished atherosclerosis $[18,26]$. Moreover, administration of sRAGE reduced atherosclerotic lesions in atherosclerotic and diabetic mice models $[4,27,28]$. Inhibition or deletion of RAGE suppressed proinflammatory activity and oxidative stress [12, 24, 29, 30]. Additionally, RAGE ligands are reported to be involved in monocyte migration and cholesterol efflux from macrophages, and the effect was diminished through anti-RAGE antibodies or sRAGE [31, 32].

In human settings, RAGE was highly expressed in plaques, retrieved after carotid endarterectomy, from diabetic patients compared to plaques from the nondiabetic patients [33] and RAGE was primarily associated with apoptotic smooth muscle cells and macrophages together with an increased proinflammatory response [33, 34]. Furthermore, increased RAGE mRNA was found in mononuclear cells also from patients with premature CAD when compared to cells from healthy controls [35]. Together these experimental and morphological studies point towards RAGE activation in I/R injury and atherosclerosis.

\section{Soluble RAGE (sRAGE)}

Soluble isoforms of RAGE are found in the circulation and may act as regulators of RAGE activity by competitive inhibition. These isoforms lack the intramembranous and intracellular parts of the receptor, which devoid intracellular signaling [36]. Soluble RAGE is produced in two different ways, either as a splice variant, esRAGE, from a truncated RAGE mRNA [6,37] or as a cleaved variant. Metalloproteinases cleave sRAGE from the full-length RAGE from the cell membrane $[5,38,39]$. So far, the concentrations of soluble RAGE have been determined as esRAGE or as the total amount of sRAGE, which are positively correlated [40, 41], and esRAGE constitutes $20 \%$ of total sRAGE [41, 42]. Different functions of the secreted and the cleaved sRAGE have not yet been demonstrated. Furthermore, sRAGE may reflect enhanced activity in the RAGE system since the effects of ligand stimulation mediate sRAGE upregulation [5] and sRAGE is secreted in parallel with RAGE $[5,6]$. This property makes sRAGE a valuable biomarker.

\section{4. sRAGE in Patients with Acute Coronary Syndrome (ACS)}

sRAGE levels in patients with ACS, defined as unstable angina, non-ST-segment elevation myocardial infarction (STEMI), and STEMI, have been presented in twelve published cohorts with diverging results (Table 1). Cai et al. and Park et al. reported elevated levels of sRAGE in patients with ACS when compared with healthy controls $[43,44]$. The study by Basta et al. did not find different sRAGE levels in non-STEMI patients compared to patients with stable CAD. However, sRAGE concentrations were higher in patients with elevated cardiac Troponin I (TnI), a specific and approved biomarker of acute myocardial infarction (AMI) [45]. In the study by Raposeiras-Roubín et al., plasma samples were collected within $12 \mathrm{hrs}$ after symptoms in relation to percutaneous coronary intervention (PCI) [46], whereas Cai et al. and Basta et al. collected the blood samples at a later time point $[43,45]$. Raposeiras-Roubín et al. reported similar sRAGE levels in STEMI and non-STEMI patients, but increased sRAGE levels were associated with poor in-hospital prognosis [46]. The time of blood sampling was not reported. Fukushima et al. found equal sRAGE levels in patients with ACS at baseline and at 8-12 months follow-up [47]. The time of baseline sampling is not described in detail, but one could speculate that blood was drawn at randomization for different statin treatment $72 \mathrm{hrs}$ after PCI.

In two different cohorts of STEMI patients, samples were drawn within $12 \mathrm{hrs}$ after onset of symptoms and before PCI. We recently reported a fourfold increase in sRAGE levels in these STEMI patients as compared to 100 healthy individuals (described in Figure 1) $[48,49]$. Successive blood samples were drawn during and after treatment of one of the STEMI cohorts, and sRAGE levels reduced almost threefold the day after PCI and decreased even further two days after PCI [49]. Interestingly, the increase of sRAGE was seen prior to TnI. The rapid decrease in sRAGE levels the day after PCI may provide valuable information in relation to diagnosis of reinfarction. Our results support the fact that sRAGE levels are elevated particularly in relation to acute ischemia, which may indicate sRAGE as an additional biomarker of AMI. In addition, the repeated measurements elucidate that sRAGE levels change over a very narrow time span in relation to acute disease. Therefore, attention to time point of sRAGE measurement is important when interpreting the results.

In contrast to the above studies, Falcone et al. found significantly decreased sRAGE levels in patients with ACS as compared to stable angina [55]. Blood samples were collected before the revascularization. Similarly, McNair et al. found lower levels of sRAGE in patients with non-STEMI compared to the controls, and time of blood sample collection was not indicated [51-54].

Only few studies have evaluated the effect of diabetes on the sRAGE levels in patients with ACS. In a group of patients (50\% with type 2 diabetes (T2D)), Park et al. reported higher plasma sRAGE levels in patients with AMI than in controls, however, regardless of the presence of diabetes [44]. Similarly, Fukushima et al. reported no differences in sRAGE levels in diabetic ACS patients (30\%) compared to nondiabetics with ACS [47]. Our two studies of STEMI patients included $6 \%$ and $9 \%$ diabetics and no difference in sRAGE levels was found due to diabetes $[48,49]$.

The ambiguity in the studies may be explained by incomparable conditions between studies; of particular importance is the time point of blood sample collection and age. A different ratio of diabetic patients within the studies described in Table 1 may also contribute to the inconclusive results as the data in diabetics with ACS are sparse. 
TABLE 1

\begin{tabular}{|c|c|c|c|}
\hline Patients & sRAGE & Description of main results & Reference \\
\hline $\begin{array}{l}\text { STEMI treated with PCI } \\
\text { with/without remote ischemic } \\
\text { conditioning }(n=191)\end{array}$ & $\uparrow$ & $\begin{array}{l}\text { Increased sRAGE levels with higher NYHA classification. } \\
\text { No effect of remote ischemic conditioning on sRAGE levels and } \\
\text { association between sRAGE and salvage index. }\end{array}$ & Jensen et al., 2015 [48] \\
\hline STEMI treated with PCI $(n=80)$ & $\uparrow$ & $\begin{array}{l}\text { Consecutive samples show high sRAGE levels prior to and } \\
\text { immediately after PCI followed by decreased levels day } 1 \text { and } \\
\text { day } 2 \text { after PCI. } \\
\text { sRAGE was an independent predictor of cardiac dysfunction } \\
\text { assessed by decreased LVEF. }\end{array}$ & Jensen et al., 2015 [49] \\
\hline $\operatorname{ACS}(n=208)$ & $\rightarrow$ & $\begin{array}{l}\text { No difference in sRAGE levels at baseline and after } 8-12 \text { months } \\
\text { after PCI. } \\
\text { Baseline sRAGE levels were not associated with plaque } \\
\text { progression } 8-12 \text { months after PCI. }\end{array}$ & $\begin{array}{l}\text { Fukushima et al., } 2013 \\
\text { [47] }\end{array}$ \\
\hline $\begin{array}{l}\text { ACS }(n=330), \text { stable angina } \\
(n=530)\end{array}$ & $\downarrow$ & $\begin{array}{l}\text { Significantly decreased sRAGE levels in ACS compared with } \\
\text { stable angina. }\end{array}$ & $\begin{array}{l}\text { Falcone et al., } 2013 \\
\text { [55] }\end{array}$ \\
\hline $\begin{array}{l}\text { STEMI }(n=102), \text { non-STEMI } \\
(n=113)\end{array}$ & $\rightarrow$ & $\begin{array}{l}\text { No difference in sRAGE levels between STEMI and non-STEMI. } \\
\text { Elevated sRAGE level was associated with in-hospital cardiac } \\
\text { events. }\end{array}$ & $\begin{array}{l}\text { Raposeiras-Roubín et } \\
\text { al., } 2013 \text { [46] }\end{array}$ \\
\hline $\begin{array}{l}\text { Non-STEMI }(n=190) \text {, stable } \\
\text { angina }(n=75)\end{array}$ & $\rightarrow \uparrow$ & $\begin{array}{l}\text { No difference in sRAGE levels between non-STEMI and stable } \\
\text { angina. } \\
\text { Increased sRAGE in patients with elevated TnI. }\end{array}$ & Basta et al., 2011 [45] \\
\hline $\begin{array}{l}\text { ACS }(n=420), \text { stable angina } \\
(n=211), \text { controls }(n=251)\end{array}$ & $\uparrow$ & Increased sRAGE levels in ACS compared with controls. & Cai et al., 2011 [43] \\
\hline AMI $(n=54)$, controls $(n=54)$ & $\uparrow$ & $\begin{array}{l}\text { Increased sRAGE levels in patients with AMI. Diabetic patients } \\
\text { with AMI had higher sRAGE levels than diabetic patients } \\
\text { without AMI. }\end{array}$ & Park et al., 2011 [44] \\
\hline $\begin{array}{l}\text { Non-STEMI }(n=36) \text {, controls } \\
(n=30)\end{array}$ & $\downarrow$ & $\begin{array}{l}\text { Lower sRAGE levels in non-STEMI compared to controls. } \\
\text { Negative correlation between sRAGE and cTnI. }\end{array}$ & $\begin{array}{l}\text { McNair et al., } 2011[51] \\
\text { McNair et al., } 2010 \\
\text { [52] }\end{array}$ \\
\hline $\begin{array}{l}\text { Non-STEMI }(n=46) \text {, controls } \\
(n=20)\end{array}$ & & $\begin{array}{l}\text { Lower sRAGE levels in non-STEMI compared to controls. } \\
\text { Non-STEMI with post-PCI restenosis had lower post-PCI } \\
\text { sRAGE levels than pre-PCI levels. }\end{array}$ & $\begin{array}{l}\text { McNair et al., } 2010 \\
{[53]}\end{array}$ \\
\hline $\begin{array}{l}\text { Non-STEMI }(n=46) \text {, controls } \\
(n=28)\end{array}$ & $\downarrow$ & $\begin{array}{l}\text { Lower sRAGE levels in non-STEMI compared to controls. } \\
\text { sRAGE levels were inversely associated with the number of } \\
\text { diseased vessels. }\end{array}$ & $\begin{array}{l}\text { McNair et al., } 2009 \\
{[54]}\end{array}$ \\
\hline
\end{tabular}

ACS: acute coronary syndrome; AMI: acute myocardial infarct; NYHA: New York Heart Association classification; LVEF: left ventricular ejection fraction; PCI: percutaneous coronary intervention; sRAGE: soluble receptor of advanced glycation end products; STEMI: ST-segment elevation myocardial infarction; TnI: Troponin I.

The major source of sRAGE in relation to ACS is still not clear, but it is highly probable that it originates from the cardiomyocytes or the vascular cells in the damaged myocardium.

\section{5. sRAGE in Patients with Stable CAD}

Opposite to the patients with ACS, patients with stable CAD had low plasma sRAGE levels when compared to controls $[35,50,56-58]$. In a large population study including 2,571 individuals, high coronary calcium score, a risk marker of CVD, was more prevalent in the group with low sRAGE levels [59]. Furthermore, in a small prospective study of patients with suspected CAD, low sRAGE levels were predictive of future cardiovascular events after 48 months of follow-up [60]. In support, low sRAGE levels in the Atherosclerosis Risk in Communities (ARIC) Study were an indicator of future
CAD after 18 years of follow-up [61]. One might speculate that the low levels of sRAGE in nondiabetic patients with stable CAD may reflect a local release of RAGE from the atherosclerotic vessels. sRAGE may capture RAGE ligands and thereby reduce measurable sRAGE in the circulation and furthermore reduce the activity in the RAGE axis.

Patients with T2D and stable CAD had significantly higher levels of sRAGE than the nondiabetic CAD patients $[58,62]$, and the T2D patients with high sRAGE concentrations had increased risk of CAD [63]. sRAGE levels were able to predict future CAD in T2D patients after approximately 4 years of follow-up [40]. In addition, high sRAGE levels were associated with an increased cardiovascular morbidity and mortality in T1D during follow-up [64, 65]. It may be speculated that the persistent high levels of sRAGE in diabetic patients may reflect an ongoing inflammatory and RAGE activity related to diabetes. 

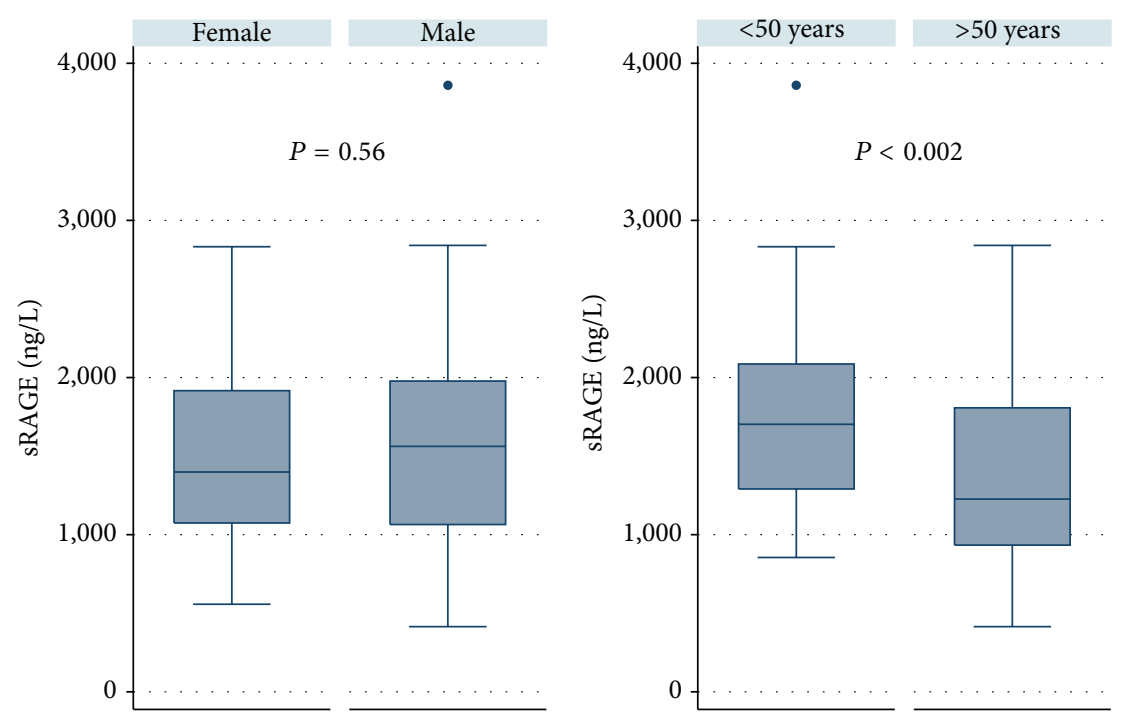

FIGURE 1: sRAGE concentrations in 100 healthy individuals. Healthy individuals are divided by gender $($ female $(n=50)$ and male $(n=50))$ or by age (below 50 years $(n=50)$ and above 50 years $(n=50)$ ).

\section{Measurement and Variation in sRAGE Levels}

As a potential biomarker, sRAGE may be influenced by detection methods and various factors such as gender, age, and ethnicity as well as diseases and medications. In the majority of published studies, sRAGE levels have been determined with a human sRAGE enzyme-linked immunosorbent assay (ELISA) (DRG00, R\&D Systems). In the enclosed datasheet, mean of sRAGE levels was 1,655 ( \pm 693 (SD)) ng/L in EDTA plasma and $1,794( \pm 693(\mathrm{SD})) \mathrm{ng} / \mathrm{L}$ in serum in apparently healthy volunteers. An extern validation revealed a stable assay with comparable concentrations in EDTA plasma and serum samples [66]. We validated a time-resolved immunofluorometric assay (TRIFMA) using commercial human RAGE antibodies (DY1145, R\&D Systems) [49] and found comparable sRAGE concentrations by TRIFMA and ELISA. We detected plasma sRAGE levels of $1,533 \mathrm{ng} / \mathrm{L}( \pm 61$ (SD)) in 100 healthy individuals. No difference in sRAGE levels was seen according to gender $(P=0.56)$, but age introduced a difference since individuals below the age of 50 had significantly higher levels of sRAGE than those above the age of $50(1,759( \pm 86(\mathrm{SD})) \mathrm{ng} / \mathrm{L}$ versus $1,378( \pm 78(\mathrm{SD}))$ ng/L, $P<0.002$, Figure 1). A negative association between age and sRAGE levels was also observed in some diabetic cohorts $[42,63]$ and in a population study [59].

sRAGE levels remained stable when repeatedly measured within at least 3 years in patients with and without diabetes [40, 42, 67]. A negative association between sRAGE levels and body mass index (BMI) has been found in some cohorts $[42,61]$ and also in one of our studies [48]. Additionally, ethnicity is reported to influence the sRAGE levels as higher sRAGE levels are reported in white compared with black individuals $[40,61,68]$. sRAGE levels may be influenced by diseases other than CAD and diabetes, for example, cancer, inflammatory diseases, neurodegenerative diseases, or chronic kidney disease [69]. Furthermore, medications may also affect sRAGE levels [70, 71].

\section{Conclusion}

Several studies indicate that RAGE activation may influence the pathogenesis and reflection in sRAGE levels in acute and stable CAD differently. The current studies demonstrated that, in nondiabetic patients, sRAGE levels are elevated in relation to ACS and sparse data indicate that diabetes does not have an additive effect in ACS patients. On the contrary, in patients with stable CAD, sRAGE levels are low in nondiabetic patients but elevated in diabetic patients which may add predictive value to recognition of future CVD.

Current data on sRAGE levels in CAD are diverging and sRAGE may be influenced by several other factors, which is why precaution must be taken with the drawn conclusions. In relation to ACS, we found the time of sampling to be of importance, which is highly relevant for evaluation as a potential biomarker. Additional mechanistic studies are needed as well as investigations of the sources and functions of sRAGE. Further clinical studies are also needed to establish the value of sRAGE as a prognostic marker in patients with ACS.

\section{Conflict of Interests}

The authors declare that there is no conflict of interests regarding the publication of this paper.

\section{References}

[1] S. Mendis, K. Thygesen, K. Kuulasmaa et al., "World Health Organization definition of myocardial infarction: 2008-09 revision," International Journal of Epidemiology, vol. 40, no. 1, Article ID dyq165, pp. 139-146, 2011. 
[2] R. Ross, "Atherosclerosis-an inflammatory disease," The New England Journal of Medicine, vol. 340, no. 2, pp. 115-126, 1999.

[3] G. K. Hansson, "Mechanisms of disease: inflammation, atherosclerosis, and coronary artery disease," The New England Journal of Medicine, vol. 352, no. 16, pp. 1626-1695, 2005.

[4] T. Wendt, L. Bucciarelli, W. Qu et al., "Receptor for advanced glycation endproducts (RAGE) and vascular inflammation: insights into the pathogenesis of macrovascular complications in diabetes," Current Atherosclerosis Reports, vol. 4, no. 3, pp. 228-237, 2002.

[5] A. Raucci, S. Cugusi, A. Antonelli et al., "A soluble form of the receptor for advanced glycation endproducts (RAGE) is produced by proteolytic cleavage of the membrane-bound form by the sheddase a disintegrin and metalloprotease 10 (ADAM10)," The FASEB Journal, vol. 22, no. 10, pp. 3716-3727, 2008.

[6] C. Schlueter, S. Hauke, A. M. Flohr, P. Rogalla, and J. Bullerdiek, "Tissue-specific expression patterns of the RAGE receptor and its soluble forms-a result of regulated alternative splicing?" Biochimica et Biophysica Acta-Gene Structure and Expression, vol. 1630, no. 1, pp. 1-6, 2003.

[7] A. Goldin, J. A. Beckman, A. M. Schmidt, and M. A. Creager, "Advanced glycation end products: sparking the development of diabetic vascular injury," Circulation, vol. 114, no. 6, pp. 597605, 2006.

[8] G. Daffu, C. H. del Pozo, K. M. O'Shea, R. Ananthakrishnan, R. Ramasamy, and A. M. Schmidt, "Radical roles for RAGE in the pathogenesis of oxidative stress in cardiovascular diseases and beyond," International Journal of Molecular Sciences, vol. 14, no. 10, pp. 19891-19910, 2013.

[9] J.-L. Wautier, M.-P. Wautier, A.-M. Schmidt et al., "Advanced glycation end products (AGEs) on the surface of diabetic erythrocytes bind to the vessel wall via a specific receptor inducing oxidant stress in the vasculature: a link between surfaceassociated AGEs and diabetic complications," Proceedings of the National Academy of Sciences of the United States of America, vol. 91, no. 16, pp. 7742-7746, 1994.

[10] M. Neeper, A. M. Schmidt, J. Brett et al., "Cloning and expression of a cell surface receptor for advanced glycosylation end products of proteins," The Journal of Biological Chemistry, vol. 267, no. 21, pp. 14998-15004, 1992.

[11] M. A. Hofmann, S. Drury, C. Fu et al., "RAGE mediates a novel proinflammatory axis: a central cell surface receptor for S100/calgranulin polypeptides," Cell, vol. 97, no. 7, pp. 889-901, 1999.

[12] M. Andrassy, H. C. Volz, J. C. Igwe et al., "High-mobility group box-1 in ischemia-reperfusion injury of the heart," Circulation, vol. 117, no. 25, pp. 3216-3226, 2008.

[13] E. Chavakis, A. Hain, M. Vinci et al., "High-mobility group box 1 activates integrin-dependent homing of endothelial progenitor cells," Circulation Research, vol. 100, no. 2, pp. 204-212, 2007.

[14] S. D. Yan, X. Chen, J. Fu et al., "RAGE and amyloid- $\beta$ peptide neurotoxicity in Alzheimer's disease," Nature, vol. 382, no. 6593, pp. 685-691, 1996.

[15] J. Chen, M. Song, S. Yu et al., "Advanced glycation endproducts alter functions and promote apoptosis in endothelial progenitor cells through receptor for advanced glycation endproducts mediate overpression of cell oxidant stress," Molecular and Cellular Biochemistry, vol. 335, no. 1-2, pp. 137-146, 2010.

[16] N. Tanaka, H. Yonekura, S.-I. Yamagishi, H. Fujimori, Y. Yamamoto, and H. Yamamoto, "The receptor for advanced glycation end products is induced by the glycation products themselves and tumor necrosis factor-alpha through nuclear factor-kappa B, and by 17beta-estradiol through Sp-1 in human vascular endothelial cells," The Journal of Biological Chemistry, vol. 275 , no. 33, pp. 25781-25790, 2000.

[17] G. Basta, G. Lazzerini, M. Massaro et al., "Advanced glycation end products activate endothelium through signaltransduction receptor RAGE: a mechanism for amplification of inflammatory responses," Circulation, vol. 105, no. 7, pp. 816822, 2002.

[18] A. Soro-Paavonen, A. M. D. Watson, J. Li et al., "Receptor for advanced glycation end products (RAGE) deficiency attenuates the development of atherosclerosis in diabetes," Diabetes, vol. 57, no. 9, pp. 2461-2469, 2008.

[19] T. Wendt, E. Harja, L. Bucciarelli et al., "RAGE modulates vascular inflammation and atherosclerosis in a murine model of type 2 diabetes," Atherosclerosis, vol. 185, no. 1, pp. 70-77, 2006.

[20] L. Park, K. G. Raman, K. J. Lee et al., "Suppression of accelerated diabetic atherosclerosis by the soluble receptor for advanced glycation endproducts," Nature Medicine, vol. 4, no. 9, pp. 10251031, 1998.

[21] L. Shang, R. Ananthakrishnan, Q. Li et al., "RAGE modulates hypoxia/reoxygenation injury in adult murine cardiomyocytes via JNK and GSK-3 $\beta$ signaling pathways," PLoS ONE, vol. 5, no. 4, Article ID e10092, 2010.

[22] Y. Tekabe, J. Luma, Q. Li, A. M. Schmidt, R. Ramasamy, and L. L. Johnson, "Imaging of receptors for advanced glycation end products in experimental myocardial ischemia and reperfusion injury," JACC: Cardiovascular Imaging, vol. 5, no. 1, pp. 59-67, 2012.

[23] A. Aleshin, R. Ananthakrishnan, Q. Li et al., "RAGE modulates myocardial injury consequent to LAD infarction via impact on JNK and STAT signaling in a murine model," The American Journal of Physiology: Heart and Circulatory Physiology, vol. 294, no. 4, pp. H1823-H1832, 2008.

[24] L. G. Bucciarelli, M. Kaneko, R. Ananthakrishnan et al., "Receptor for advanced-glycation end products: key modulator of myocardial ischemic injury," Circulation, vol. 113, no. 9, pp. 1226-1234, 2006.

[25] X. Jiang, C. X. Guo, X. J. Zeng, H. H. Li, B. X. Chen, and F. H. Du, "A soluble receptor for advanced glycation end-products inhibits myocardial apoptosis induced by ischemia/reperfusion via the JAK2/STAT3 pathway," Apoptosis, vol. 20, no. 8, pp. 10331047, 2015.

[26] E. Harja, D.-X. Bu, B. I. Hudson et al., "Vascular and inflammatory stresses mediate atherosclerosis via RAGE and its ligands in apoE ${ }^{-/-}$mice," The Journal of Clinical Investigation, vol. 118, no. 1, pp. 183-194, 2008.

[27] L. G. Bucciarelli, T. Wendt, W. Qu et al., "RAGE blockade stabilizes established atherosclerosis in diabetic apolipoprotein E-null mice," Circulation, vol. 106, no. 22, pp. 2827-2835, 2002.

[28] C. H. Ha, S. Kim, J. Chung et al., "Inhibitory effect of soluble RAGE in disturbed flow-induced atherogenesis," International Journal of Molecular Medicine, vol. 32, no. 2, pp. 373-380, 2013.

[29] Y. Sun, "Myocardial repair/remodelling following infarction: roles of local factors," Cardiovascular Research, vol. 81, no. 3, pp. 482-490, 2009.

[30] S. D. Yan, A. M. Schmidt, G. M. Anderson et al., "Enhanced cellular oxidant stress by the interaction of advanced glycation end products with their receptors/binding proteins," The Journal of Biological Chemistry, vol. 269, no. 13, pp. 9889-9897, 1994. 
[31] K. Isoda, E. J. Folco, K. Shimizu, and P. Libby, "AGE-BSA decreases ABCG1 expression and reduces macrophage cholesterol efflux to HDL," Atherosclerosis, vol. 192, no. 2, pp. 298-304, 2007.

[32] A. Rouhiainen, J. Kuja-Panula, E. Wilkman et al., "Regulation of monocyte migration by amphoterin (HMGB1)," Blood, vol. 104, no. 4, pp. 1174-1182, 2004.

[33] F. Cipollone, A. Iezzi, M. Fazia et al., "The receptor RAGE as a progression factor amplifying arachidonate-dependent inflammatory and proteolytic response in human atherosclerotic plaques: role of glycemic control," Circulation, vol. 108, no. 9, pp. 1070-1077, 2003.

[34] A. P. Burke, F. D. Kolodgie, A. Zieske et al., "Morphologic findings of coronary atherosclerotic plaques in diabetics: a postmortem study," Arteriosclerosis, Thrombosis, and Vascular Biology, vol. 24, no. 7, pp. 1266-1271, 2004.

[35] N. Mahajan, N. Malik, A. Bahl, and V. Dhawan, "Receptor for advanced glycation end products (RAGE) and its inflammatory ligand EN-RAGE in non-diabetic subjects with pre-mature coronary artery disease," Atherosclerosis, vol. 207, no. 2, pp. 597602, 2009.

[36] H. Yonekura, Y. Yamamoto, S. Sakurai et al., "Novel splice variants of the receptor for advanced glycation end-products expressed in human vascular endothelial cells and pericytes, and their putative roles in diabetes-induced vascular injury," Biochemical Journal, vol. 370, no. 3, pp. 1097-1109, 2003.

[37] P. Malherbe, J. G. Richards, H. Gaillard et al., "cDNA cloning of a novel secreted isoform of the human receptor for advanced glycation end products and characterization of cells co-expressing cell-surface scavenger receptors and Swedish mutant amyloid precursor protein," Molecular Brain Research, vol. 71, no. 2, pp. 159-170, 1999.

[38] A. Galichet, M. Weibel, and C. W. Heizmann, "Calciumregulated intramembrane proteolysis of the RAGE receptor," Biochemical and Biophysical Research Communications, vol. 370, no. 1, pp. 1-5, 2008.

[39] L. Zhang, M. Bukulin, E. Kojro et al., "Receptor for advanced glycation end products is subjected to protein ectodomain shedding by metalloproteinases," Journal of Biological Chemistry, vol. 283, no. 51, pp. 35507-35516, 2008.

[40] H. M. Colhoun, D. J. Betteridge, P. Durrington et al., “Total soluble and endogenous secretory receptor for advanced glycation end products as predictive biomarkers of coronary heart disease risk in patients with type 2 diabetes: an analysis from the CARDS trial," Diabetes, vol. 60, no. 9, pp. 2379-2385, 2011.

[41] P. M. Humpert, Z. Djuric, S. Kopf et al., "Soluble RAGE but not endogenous secretory RAGE is associated with albuminuria in patients with type 2 diabetes," Cardiovascular Diabetology, vol. 6, article 9, 2007.

[42] N. Katakami, M. Matsuhisa, H. Kaneto et al., "Serum endogenous secretory RAGE level is an independent risk factor for the progression of carotid atherosclerosis in type 1 diabetes," Atherosclerosis, vol. 204, no. 1, pp. 288-292, 2009.

[43] X. Y. Cai, L. Lu, Y. N. Wang et al., "Association of increased S100B, S100A6 and S100P in serum levels with acute coronary syndrome and also with the severity of myocardial infarction in cardiac tissue of rat models with ischemia-reperfusion injury," Atherosclerosis, vol. 217, no. 2, pp. 536-542, 2011.

[44] H.-J. Park, J.-Y. Baek, W. S. Shin et al., "Soluble receptor of advanced glycated endproducts is associated with plaque vulnerability in patients with acute myocardial infarction," Circulation Journal, vol. 75, no. 7, pp. 1685-1690, 2011.
[45] G. Basta, S. Del Turco, F. Marchi et al., "Elevated soluble receptor for advanced glycation end product levels in patients with acute coronary syndrome and positive cardiac troponin I," Coronary Artery Disease, vol. 22, no. 8, pp. 590-594, 2011.

[46] S. Raposeiras-Roubín, B. K. Rodiño-Janeiro, B. ParadelaDobarro et al., "Fluorescent advanced glycation end products and their soluble receptor: the birth of new plasmatic biomarkers for risk stratification of acute coronary syndrome," PLoS ONE, vol. 8, no. 9, Article ID e74302, 2013.

[47] Y. Fukushima, H. Daida, T. Morimoto et al., "Relationship between advanced glycation end products and plaque progression in patients with acute coronary syndrome: the JAPAN-ACS sub-study," Cardiovascular Diabetology, vol. 12, no. 1, article 5, 2013.

[48] L. J. Jensen, K. Munk, A. Flyvbjerg, H. E. Botker, and M. Bjerre, "Soluble receptor of advanced glycation end-products in patients with acute myocardial infarction treated with remote ischaemic conditioning," Clinical Laboratory, vol. 61, no. 3-4, pp. 323-328, 2015.

[49] L. J. N. Jensen, S. Lindberg, S. Hoffmann et al., "Dynamic changes in sRAGE levels and relationship with cardiac function in STEMI patients," Clinical Biochemistry, vol. 48, no. 4-5, pp. 297-301, 2015.

[50] C. Falcone, S. Bozzini, L. Guasti et al., "Soluble RAGE plasma levels in patients with coronary artery disease and peripheral artery disease," The Scientific World Journal, vol. 2013, Article ID 584504, 7 pages, 2013.

[51] E. D. McNair, C. R. Wells, A. M. Qureshi, C. Pearce, G. CasparBell, and K. Prasad, "Inverse association between cardiac troponin-I and soluble receptor for advanced glycation end products in patients with non-ST-segment elevation myocardial infarction," International Journal of Angiology, vol. 20, no. 1, pp. 49-54, 2011.

[52] E. D. McNair, C. R. Wells, A. M. Qureshi et al., "Modulation of high sensitivity C-reactive protein by soluble receptor for advanced glycation end products," Molecular and Cellular Biochemistry, vol. 341, no. 1-2, pp. 135-138, 2010.

[53] E. D. McNair, C. R. Wells, A. Mabood Qureshi et al., "Soluble receptors for advanced glycation end products (sRAGE) as a predictor of restenosis following percutaneous coronary intervention," Clinical Cardiology, vol. 33, no. 11, pp. 678-685, 2010.

[54] E. D. McNair, C. R. Wells, A. M. Qureshi et al., "Low levels of soluble receptor for advanced glycation end products in non-ST elevation myocardial infarction patients," International Journal of Angiology, vol. 18, no. 4, pp. 187-192, 2009.

[55] C. Falcone, S. Bozzini, A. D’Angelo et al., "Plasma levels of soluble receptor for advanced glycation end products and coronary atherosclerosis: possible correlation with clinical presentation," Disease Markers, vol. 35, no. 3, pp. 135-140, 2013.

[56] C. Falcone, E. Emanuele, A. D’Angelo et al., "Plasma levels of soluble receptor for advanced glycation end products and coronary artery disease in nondiabetic men," Arteriosclerosis, Thrombosis, and Vascular Biology, vol. 25, no. 5, pp. 1032-1037, 2005.

[57] V. Danzig, B. Míková, P. Kuchynka et al., "Levels of circulating biomarkers at rest and after exercise in coronary artery disease patients," Physiological Research, vol. 59, no. 3, pp. 385-392, 2010.

[58] X. X. Yan, L. Lu, W. H. Peng et al., "Increased serum HMGB1 level is associated with coronary artery disease in nondiabetic and type 2 diabetic patients," Atherosclerosis, vol. 205, no. 2, pp. 544-548, 2009. 
[59] J. B. Lindsey, J. A. de Lemos, F. Cipollone et al., "Association between circulating soluble receptor for advanced glycation end products and atherosclerosis: observations from the Dallas Heart Study," Diabetes Care, vol. 32, no. 7, pp. 1218-1220, 2009.

[60] K.-H. Chiang, P.-H. Huang, S.-S. Huang, T.-C. Wu, J.-W. Chen, and S.-J. Lin, "Plasma levels of soluble receptor for advanced glycation end products are associated with endothelial function and predict cardiovascular events in nondiabetic patients," Coronary Artery Disease, vol. 20, no. 4, pp. 267-273, 2009.

[61] E. Selvin, M. K. Halushka, A. M. Rawlings et al., "sRAGE and risk of diabetes, cardiovascular disease, and death," Diabetes, vol. 62, no. 6, pp. 2116-2121, 2013.

[62] K. Nakamura, S.-I. Yamagishi, H. Adachi et al., "Elevation of soluble form of receptor for advanced glycation end products (sRAGE) in diabetic subjects with coronary artery disease," Diabetes/Metabolism Research and Reviews, vol. 23, no. 5, pp. 368-371, 2007.

[63] K. Fujisawa, N. Katakami, H. Kaneto et al., "Circulating soluble RAGE as a predictive biomarker of cardiovascular event risk in patients with type 2 diabetes," Atherosclerosis, vol. 227, no. 2, pp. 425-428, 2013.

[64] M. C. Thomas, J. Söderlund, M. Lehto et al., "Soluble receptor for AGE (RAGE) is a novel independent predictor of all-cause and cardiovascular mortality in type 1 diabetes," Diabetologia, vol. 54, no. 10, pp. 2669-2677, 2011.

[65] J. W. M. Nin, A. Jorsal, I. Ferreira et al., "Higher plasma soluble receptor for advanced glycation end products (sRAGE) levels are associated with incident cardiovascular disease and allcause mortality in type 1 diabetes: a 12 -year follow-up study," Diabetes, vol. 59, no. 8, pp. 2027-2032, 2010.

[66] C. Wittwer, J. Lehner, D. Fersching, B. Siegele, O. J. Stoetzer, and S. Holdenrieder, "Methodological and preanalytical evaluation of a RAGE immunoassay," Anticancer Research, vol. 32, no. 5, pp. 2075-2078, 2012.

[67] J. K. Bower, J. S. Pankow, M. Lazo et al., “Three-year variability in plasma concentrations of the soluble receptor for advanced glycation end products (sRAGE)," Clinical Biochemistry, vol. 47, no. 1-2, pp. 132-134, 2014.

[68] B. I. Hudson, Y. P. Moon, A. Z. Kalea et al., "Association of serum soluble receptor for advanced glycation end-products with subclinical cerebrovascular disease: the Northern Manhattan Study (NOMAS)," Atherosclerosis, vol. 216, no. 1, pp. 192-198, 2011.

[69] N. Vazzana, F. Santilli, C. Cuccurullo, and G. Davì, "Soluble forms of RAGE in internal medicine," Internal and Emergency Medicine, vol. 4, no. 5, pp. 389-401, 2009.

[70] H. Koyama, S. Tanaka, M. Monden et al., "Comparison of effects of pioglitazone and glimepiride on plasma soluble RAGE and RAGE expression in peripheral mononuclear cells in type 2 diabetes: randomized controlled trial (PioRAGE)," Atherosclerosis, vol. 234, no. 2, pp. 329-334, 2014.

[71] H. L. Tam, S. W. M. Shiu, Y. Wong, W. S. Chow, D. J. Betteridge, and K. C. B. Tan, "Effects of atorvastatin on serum soluble receptors for advanced glycation end-products in type 2 diabetes," Atherosclerosis, vol. 209, no. 1, pp. 173-177, 2010. 


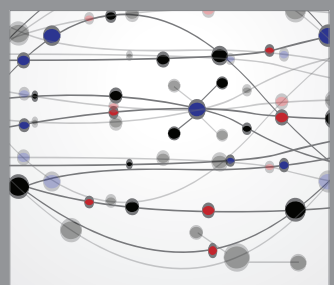

The Scientific World Journal
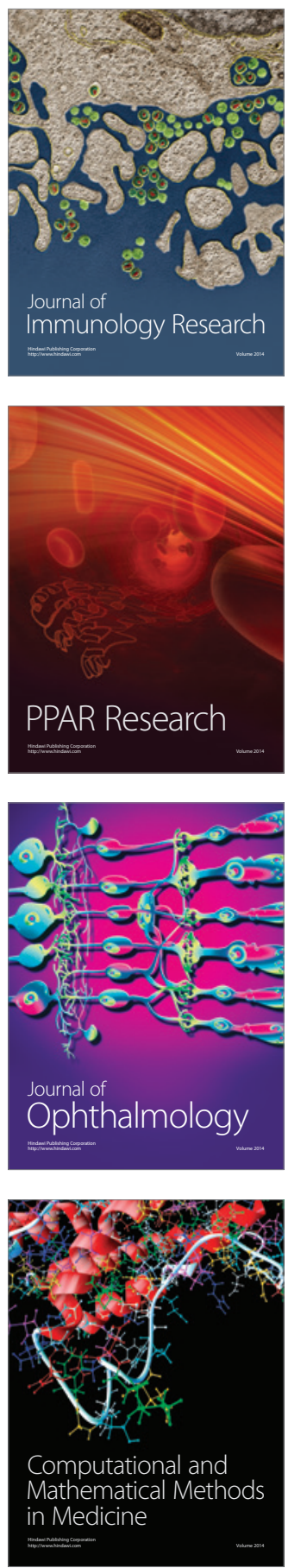

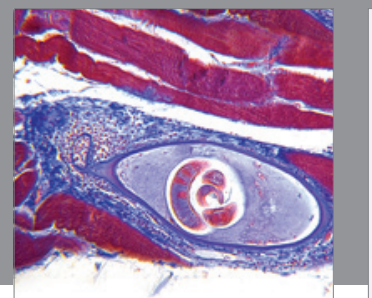

Gastroenterology

Research and Practice
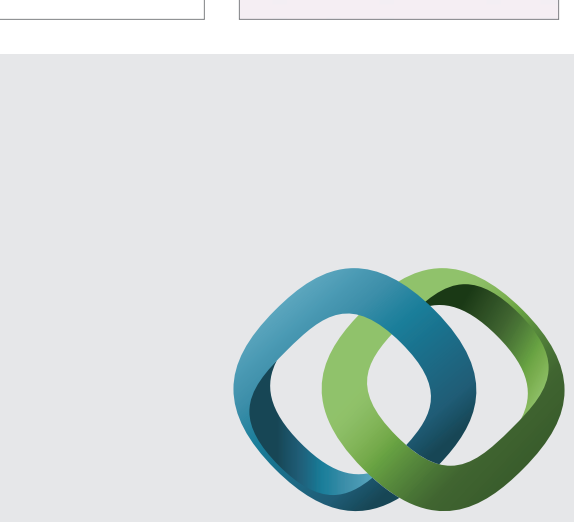

\section{Hindawi}

Submit your manuscripts at

http://www.hindawi.com
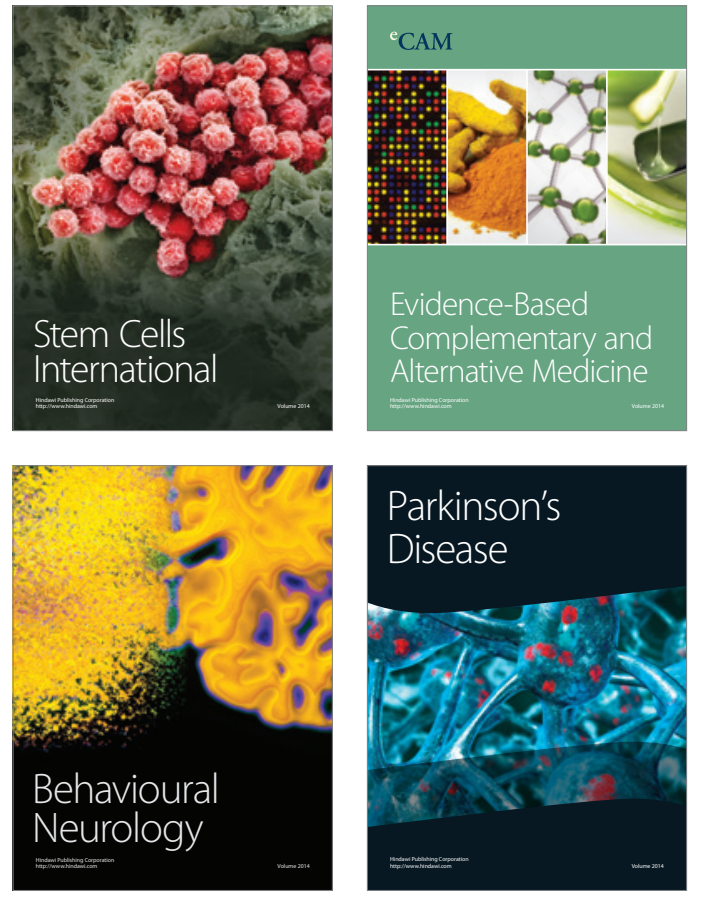
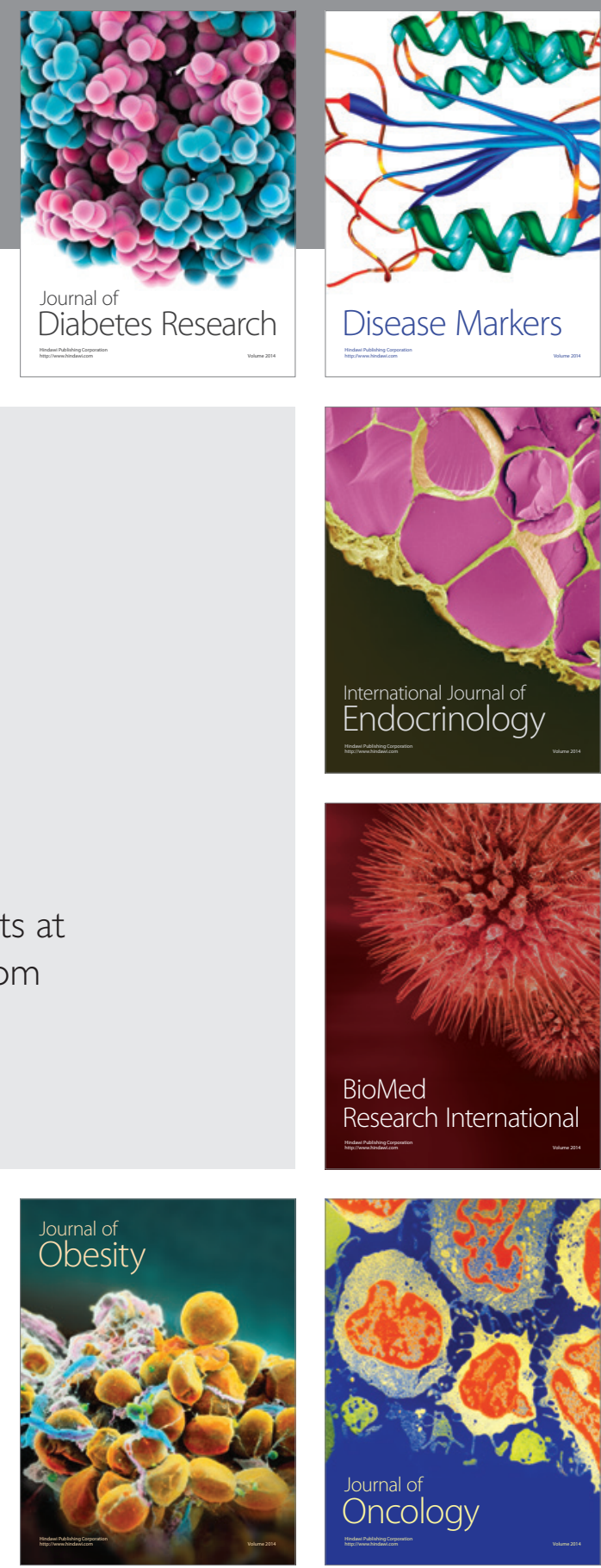

Disease Markers
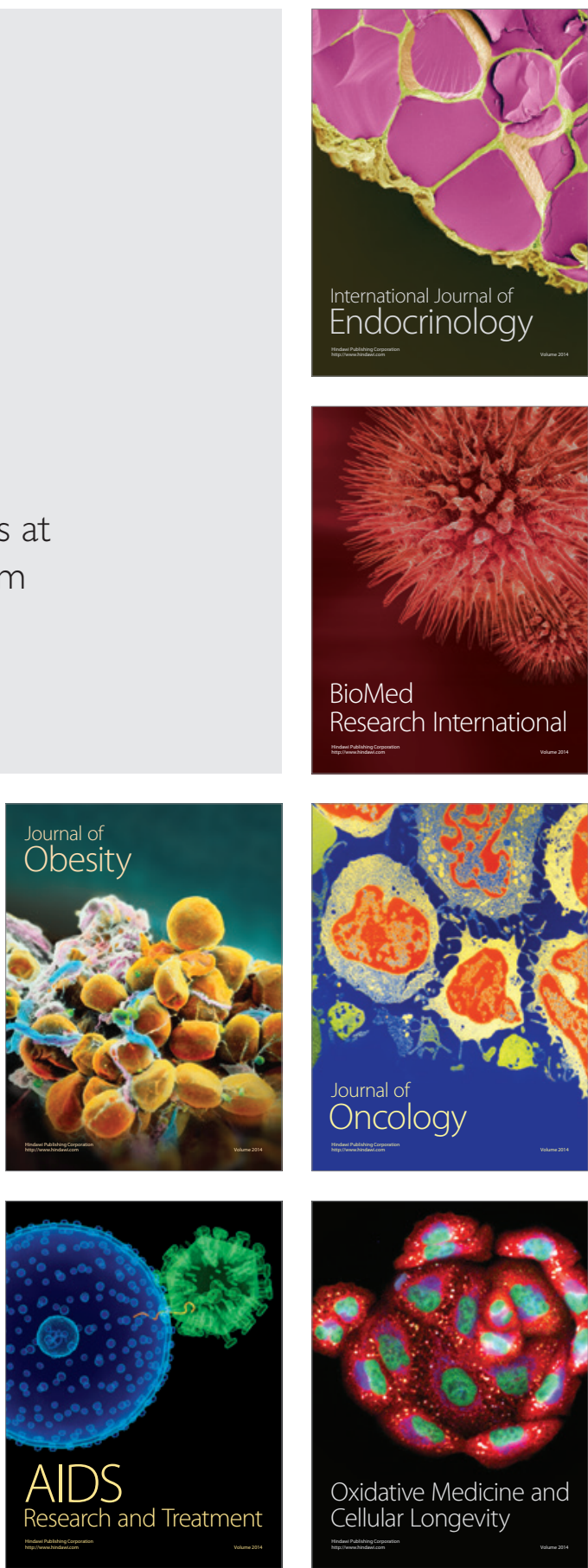